\title{
COMPARATIVE STUDY OF FUNCTIONAL OUTCOME OF OPERATIVE AND NON-OPERATIVE TREATMENT IN MIDSHAFT CLAVICLE FRACTURES
}

\author{
R. Sahaya Jose ${ }^{1}$ \\ ${ }^{1}$ Assistant Professor, Department of Orthopaedics, Sree Mookambika Institute of Medical Sciences.
}

ABSTRACT: Clavicle is one of the commonest bone, which gets fractured. In which, midshaft fractures account for 80 percent of all clavicle fractures when compared to lateral and medial third clavicle fractures. The surgical indications for midshaft clavicle fractures are controversial. Controversy exists over management of midshaft clavicle fractures with substantial displacement and shortening ( $>1$ to $2 \mathrm{~cm}$ ). Although most displaced midshaft clavicle fractures will unite, studies have reported shoulder dysfunction and patient dissatisfaction with the resulting cosmetic deformity. In our study, we have compared and evaluated the short-term functional outcome of patients who has been treated operatively and non-operatively for midshaft clavicle fractures using Constant and Murley Scoring system. Ours is a prospective, non-randomised, case-control study of 28 patients who has undergone surgical management and 23 patients who took non-operative treatment for midshaft clavicle fractures done from April 2013 to October 2015. Our surgical modality of treatment is open reduction and internal fixation with plate osteosynthesis using standard anterior approach to clavicle. We have used Edinburgh Classification to classify the clavicle fractures. Statistics analysis done by SPSS 16.0 (Statistical package for social science). With the results of our study we have come to a conclusion that there were no significant difference in functional outcome of patients with midshaft clavicle fractures treated by surgery and non-surgically. Shortening of more than 2 centimeters did not affect the final scores and functional outcome of patients.

KEYWORDS: Midshaft Clavicle Fracture, Constant and Murley Scoring System, Edinburgh Classification.

HOW TO CITE THIS ARTICLE: R. Sahaya Jose. "Comparative Study of Functional Outcome of Operative and Non-Operative Treatment in Midshaft Clavicle Fractures." Journal of Evolution of Medical and Dental Sciences 2015; Vol. 4, Issue 94, November 23; Page: 15982-15993, DOI: 10.14260/jemds/2015/2330.

INTRODUCTION: Midshaft clavicle fractures account for 80 percent of all clavicle fractures when compared to medial and lateral third clavicle fractures. The junction between the two cross-sectional configurations occur in the midshaft and consitutes a vulnerable area to fracture, especially with axial loading. Moreover midshaft lacks reinforcement by muscles or ligaments distal to the subclavius insertion resulting in additional vulnerability. The surgical indication for midshaft clavicle fractures are controversial. Controversy still exists over management of midshaft clavicle fractures with gross displacement and shortening. Main controversy lies between whether there are any significant differences in fuctional outcome between surgical and non-surgical treatment of midshaft clavicle fractures. Also, whether patients with shortening $>2$ centimetres have more fuctional deficit than patients with shortening $<2$ centimetres. We classified clavicle fractures using Edinburgh Classification. ${ }^{1}$ In our centre, we have decided to compare and evaluate the shortterm functional outcome of operative and non-operative treatment of midshaft clavicle fracture using Constant and Murley Scoring system. ${ }^{2}$

AIMS OF THE STUDY: To compare the functional outcome of patients who has been treated operatively and nonoperatively for midshaft clavicle fractures.

Financial or Other, Competing Interest: None.

Submission 03-11-2015, Peer Review 04-11-2015,

Acceptance 13-11-2015, Published 23-11-2015.

Corresponding Author:

Dr. R. Sahaya Jose,

119-Jose Bhavan, Puthukudieruppu,

Nagercoil-629001. Kanyakumari,

Tamil Nadu, India.

E-mail:drjose07@yahoo.co.in

DOI:10.14260/jemds/2015/2330.
MATERIALS AND METHODS: The present study has totally 51 cases, which includes 28 patients who has undergone surgical management and 23 patients who took nonoperative treatment for midshaft clavicle fractures from April 2013 to October 2015. It is a prospective non-randomised case control study. For all the surgical cases, we used the standard anterior approach. ${ }^{3,5}$ to clavicle. We used open reduction and internal fixation with plate osteosynthesis as our surgical modality.

We used reconstruction plate and pre-contoured clavicle plates for surgery. To find out the effect of age in functional outcome, the patients in both groups were arbitrarily subdivided into 3 groups. Group I ( $<30$ years), Group II (30-50 years), Group III ( $>50$ years). In operative group 11 patients fell in Group I, 12 patients fell in Group II, and 5 patients in Group III category. Whereas in nonoperative group, 6 patients fell in Group I, 8 patients fell in Group II, and 9 patients fell in Group III category. Our study does not have any bilateral clavicle cases. Postoperatively, Broad arm sling was given for 4-6 weeks.

Gentle shoulder mobilisation started once pain decreases and progressive increase in ROM as tolerated. Nonoperative cases were treated with broad arm sling and figureof-8 bracing. ROM initiated either early or after 3 weeks and progressive increase in ROM activity of upper limb as tolerated.

FOLLOW-UP: Patients were reviewed regularly at 6 weeks, 6 months, 1 year, and then yearly. Patients were assessed radiologically and clinically using Constant and Murley scoring system. Shortening is measured clinically by using Calipers. 


\section{Inclusion Criteria:}

- Mid shaft clavicle fracture in adults,

- Treated surgically and nonsurgically,

CLASSIFICATION RESULTS:

- Minimum follow-up of six months.

\section{Exclusion Criteria:}

- Paediatric clavicle fractures,

- Undisplaced fractures,

- Floating shoulder injuries,

- Open clavicle fractures,

- Fractures of ipsilateral upper extremity,

- Cervical spine injuries with neurological deficit,

- Associated pre-existing neurological deficits of same extremity.

\section{RESULTS:}

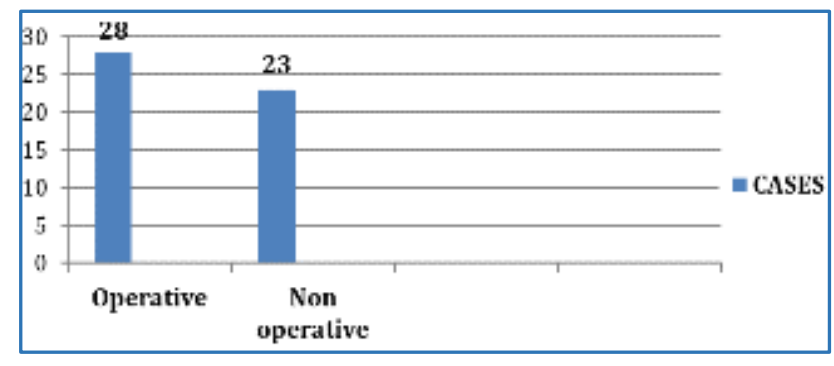

Fig. 1: Number of Cases

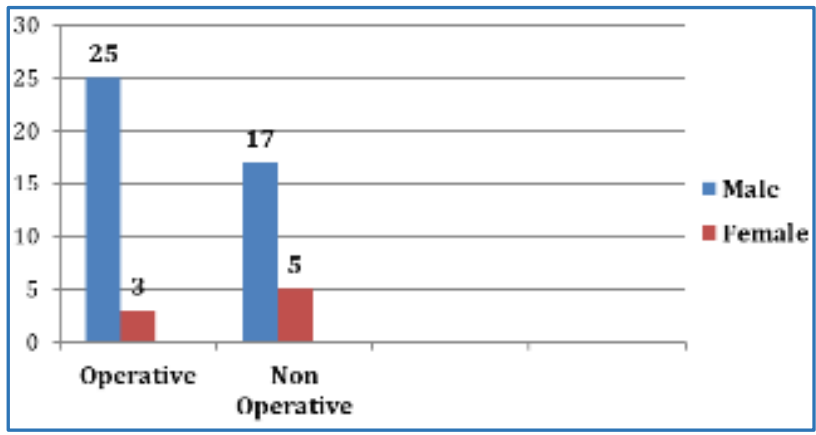

Fig. 2: Sex Ratio

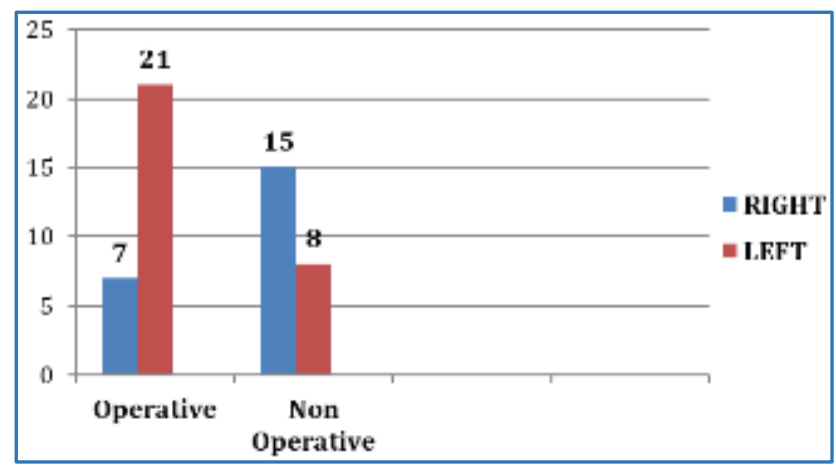

Fig. 3: Side

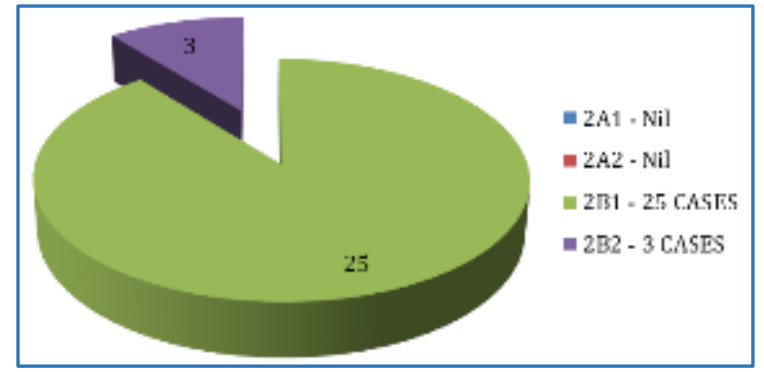

Fig. 4: Operative

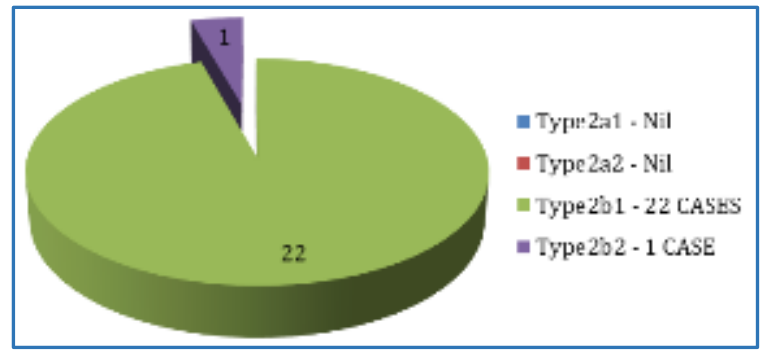

Fig. 5: Non-Operative

\section{CLASSIFICATION RESULTS:}

\begin{tabular}{|c|c|c|}
\hline TYPE 2B1 & OPERATIVE & $\begin{array}{c}\text { NON- } \\
\text { OPERATIVE }\end{array}$ \\
\hline EXCELLENT & 13 & 7 \\
\hline GOOD & 7 & 7 \\
\hline FAIR & 4 & 6 \\
\hline POOR & 1 & 2 \\
\hline & 25 & 22 \\
\hline
\end{tabular}

\begin{tabular}{|c|c|c|}
\hline TYPE 2B2 & OPERATIVE & NON-OPERATIVE \\
\hline EXCELLENT & 1 & 0 \\
\hline GOOD & 0 & 0 \\
\hline FAIR & 0 & 1 \\
\hline POOR & 2 & 0 \\
\hline & 3 & 1 \\
\hline
\end{tabular}

\section{SHORTENING}

\begin{tabular}{|c|c|c|}
\hline & $\mathbf{2} \mathbf{C M}$ & $\mathbf{2} \mathbf{O R} \mathbf{>} \mathbf{2 m}$ \\
\hline Operative & 23 cases & 5 cases \\
\hline Non-operative & 21 cases & 2 cases \\
\hline
\end{tabular}

\begin{tabular}{|c|c|c|}
\hline Operative & $\mathbf{2} \mathbf{c m}$ & $\mathbf{2 ~ O R} \mathbf{2} \mathbf{c m}$ \\
\hline Excellent & 12 & 2 \\
\hline Good & 6 & 1 \\
\hline Fair & 3 & 1 \\
\hline Poor & 2 & 1 \\
\hline
\end{tabular}

\begin{tabular}{|c|c|c|}
\hline Non Operative & $\mathbf{> 2 c m}$ & 2 OR $\mathbf{2} \mathbf{c m}$ \\
\hline Excellent & 6 & 1 \\
\hline Good & 6 & 1 \\
\hline Fair & 7 & 0 \\
\hline Poor & 2 & 0 \\
\hline
\end{tabular}


GRADING

\begin{tabular}{|c|c|c|}
\hline & OPERATIVE & NON-OPERATIVE \\
\hline EXCELLENT & 14 & 7 \\
\hline GOOD & 7 & 7 \\
\hline FAIR & 4 & 7 \\
\hline POOR & 3 & 2 \\
\hline & 28 & 23 \\
\hline
\end{tabular}

\section{COMPLICATIONS}

\begin{tabular}{|c|c|c|}
\hline & OPERATIVE & $\begin{array}{c}\text { NON- } \\
\text { OPERATIVE }\end{array}$ \\
\hline Non-union & 2 & 5 \\
\hline Mal-union & 7 & 18 \\
\hline $\begin{array}{c}\text { Shoulder } \\
\text { restriction }\end{array}$ & 4 & 4 \\
\hline Implant failure & 2 & 0 \\
\hline Infection & 28 & 23 \\
\hline Others & 4 (op site numbness) & \\
\hline
\end{tabular}

DISCUSSION: Fracture clavicle have been treated nonoperatively in most of the previous studies. Although a malunion was the sequelae in most of these patients, it was thought that these patients did not have any functional problems related to the malunion. However, recent studies have shown that a subset of patients with malunions of the mid-shaft clavicular fractures do have functional deficits. These have been classified as Orthopedic, Neurologic and Cosmetic. These include weakness of the affected shoulder, decreased endurance, parasthesias of the affected upper extremity and cosmetic deformities like "Drooping" or "Ptosis" of the shoulder. McKee et al. presented their series on patients who had corrective osteotomy for malunions of the middle third clavicle fractures.

There were fifteen patients who had one or combination of that above mentioned symptoms. The mean shortening on the clavicle was $2.9 \mathrm{~cm}(1.6 \mathrm{~cm}$ to $4 \mathrm{~cm})$. The preoperative DASH score improved from 32 points to 12 points at the time of final followup. The shortening improved from $2.9 \mathrm{~cm}$ to $0.4 \mathrm{~cm}$. The authors concluded that malunion of the clavicle may not be asymptomatic as previously thought and corrective osteotomy gives high degree of patient satisfaction in selected cases. Similar results were found with corrective osteotomy by Basamania, Bosch and Chan.6,8

In a meta-analysis of clavicle fractures, Zlowodski et al., ${ }^{9}$ the rates of non-union following clavicle fractures have been $2.2 \%$ after plate fixation and $15.1 \%$ following non-operative treatment. The relative risk reduction for non-union following plate fixation was $86 \%$.

\section{Non-union}

\begin{tabular}{|c|c|c|}
\hline & Zlowodski et al. & Our Study \\
\hline Operative & $2.2 \%$ & $7.14 \%$ \\
& (10 of 460 patients) & (2 of 28 patients) \\
\hline Non-operative & $15.1 \%$ & $21.73 \%$ \\
& (24 of 159 patients) & (5 of 23 patients) \\
\hline
\end{tabular}

The meta-analysis showed that plate fixation was a reliable and safe procedure. In a multi-center RCT comparing non-operative and operative treatment of clavicular fractures, The Canadian Orthopedic Society examined the results of 132 patients who had middle-third clavicle fractures; 67 were treated with plate fixation and 65 nonoperatively. Constant shoulder scores and DASH scores were significantly better in the operative group compared to the non-operative group. Symptomatic malunion was more in the non-operative group. However, the incidence of hardware irritation and implant related infection were more in the operative group. The authors concluded that operative treatment of clavicle fractures resulted in improved functional outcome and lower rate of malunion and nonunion.

Our study aimed at finding out if there was any significant differences in functional outcome between surgical and non-surgical treatment of midshaft clavicular fractures. We also wanted to find out whether the patients with shortening of more than $2 \mathrm{cms}$ had more functional deficit compared to patients who had less than $2 \mathrm{~cm}$ shortening.

In our study, there were 28 patients in the operative group. The Constant and Murley score was chosen because it evaluated subjective, objective and functional criteria. It is simple to understand and easy to use with low inter-intra observer error. In the operative group, 14 patients had excellent result, 7 had good, 4 had fair and 3 had poor results.

The patients who had poor results had not carried out exercises as prescribed leading to development of stiff shoulder. The restriction of movement is reflected as a low score, because the scoring system is considerably influenced by the ROM of the shoulder. There were no malunions, but two fractures went in for non-union. One of these patients had a fall and had implant failure.

The other patient had a back out of one screw leading to loss of fixation leading to non-union. There were no infections. Four patients had numbness in the infra-clavicular region. Of interest is the fact that one of the patient who had implant failure and non-union had a good result. He was professionally and recreationally fully functional and declined revision surgery. He however complained on discomfort of his affected shoulder on leading questioning.

In our study, there were 23 patients in the nonoperative treatment; 7 had excellent results, 7 had good results, 7 had fair results and 2 had poor results. Out of these 21 had shortening of less than $2 \mathrm{~cm}, 2$ patients had shortening of more than $2 \mathrm{cms}, 5$ patients had non-union and 18 patients had radiological malunion. Of the five patients who had nonunion, the Constant and Murley score was Fair.

The mean Constant and Murley score in the operated group was 72.14 and that in the non-operative group was 63.83. This difference was not found to be statistically significant $(\mathrm{P}=0.163)$ (Table 1$)$.

\begin{tabular}{|c|c|c|c|}
\hline $\begin{array}{c}\text { Type of } \\
\text { Management }\end{array}$ & Cases & Mean & $\begin{array}{c}\text { Standard } \\
\text { Deviation }\end{array}$ \\
\hline $\begin{array}{c}\text { Operative } \\
\text { Non-operative }\end{array}$ & 28 & 72.14 & 21.547 \\
\hline \multicolumn{3}{|c|}{ Table 1: Functional Results } \\
\hline
\end{tabular}

$P$ value $=0.163$ not statistically significant 
This would also imply that shortening of more than $2 \mathrm{cms}$, which was found in patients only in the non-operative group did not affect the final outcome scores significantly.

To find out the effect of age on the functional outcome, the patients in both groups were arbitrarily subdivided into three age groups, i.e., Group 1 (30 yrs $>$ ), Group 2 (30-50 yrs) and Group $3(50$ yrs $<)$. In the operative group ( $n=28)$. Group 1 had 11 patients, 9 had excellent results, 1 had good and only 1 had poor outcome scores. In Group 2 (n=12), 4 had excellent, 4 had good, 3 had fair and 1 had poor outcome scores. In Group $3(\mathrm{n}=5)$, only 1 had excellent, 2 had good, 1 had fair and 1 had poor results. (Table-2)

\begin{tabular}{|c|c|c|c|}
\hline Age & No. of Patients & Mean & Standard Deviation \\
\hline$<30$ & 11 & 81.91 & 18.398 \\
\hline 30.50 & 12 & 68.08 & 19.421 \\
\hline$>50$ & 5 & 60.40 & 27.682 \\
\hline \multicolumn{4}{|c|}{ Table 2: Operative } \\
\hline
\end{tabular}

$P$ value $=0.120$ not statistically significant

In the non-operative group ( $\mathrm{n}=23)$; Group $1(\mathrm{n}=6) 4$ had excellent, 1 had good and 1 had fair results. Group $2(\mathrm{~m}=8), 3$ had excellent, 2 had good and 3 had fair outcomes. Group 3 $(n=9), 4$ had good results, 3 had fair and 2 had poor results. Younger patients seemed to have had better scores than old patients on comparison.

\begin{tabular}{|c|c|c|c|}
\hline Age & No. of Patients & Mean & Standard Deviation \\
\hline$<30$ & 6 & 73.33 & 19.180 \\
\hline 30.50 & 8 & 67.13 & 21.067 \\
\hline$>50$ & 9 & 54.56 & 17.494 \\
\hline \multicolumn{4}{|c|}{ Table 3: Non-operative } \\
\hline
\end{tabular}

$P$ value $=0.557$ not statistically significant

Five patients in the non-operative group who had excellent results were analyzed separately. All these patients had mobilization of their shoulders earlier than the others in the group. This probably played a role in producing better outcome scores in this group of patients.

\section{OPERATIVE CASE 1 - 18 yr/M - Excellent result}

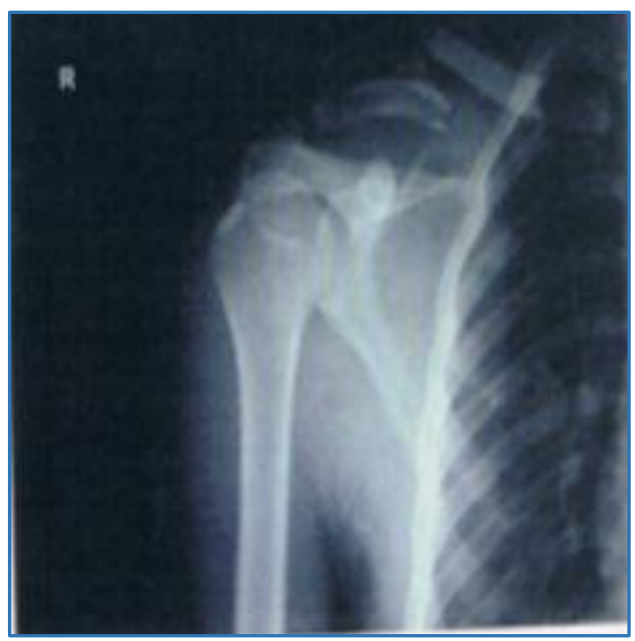

Preoperative

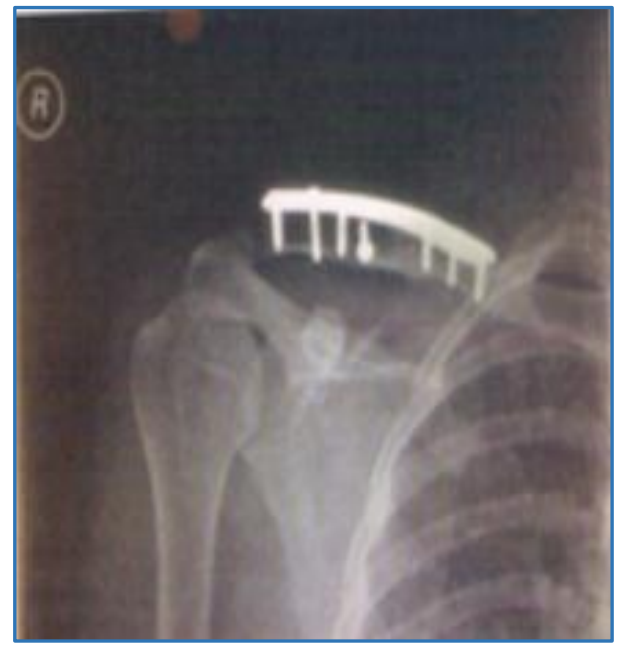

Fig. 2: Postop 1 year

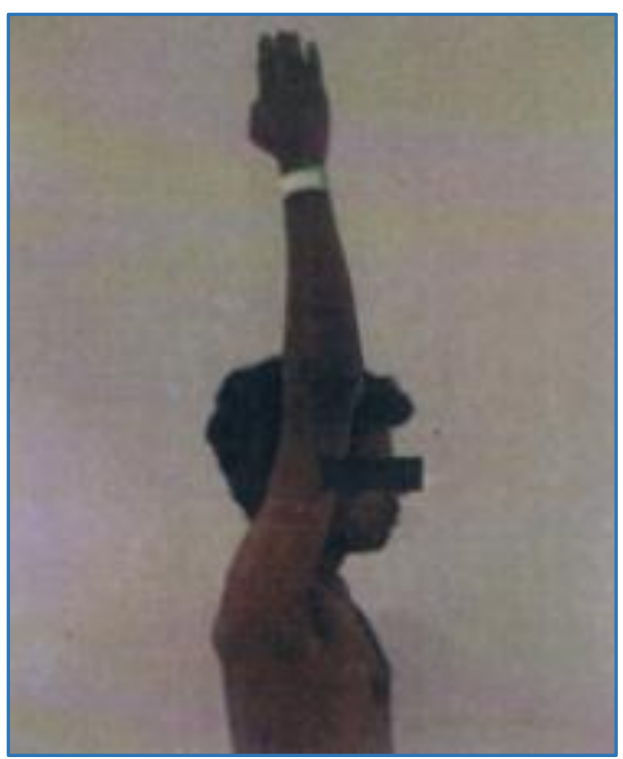

Flexion

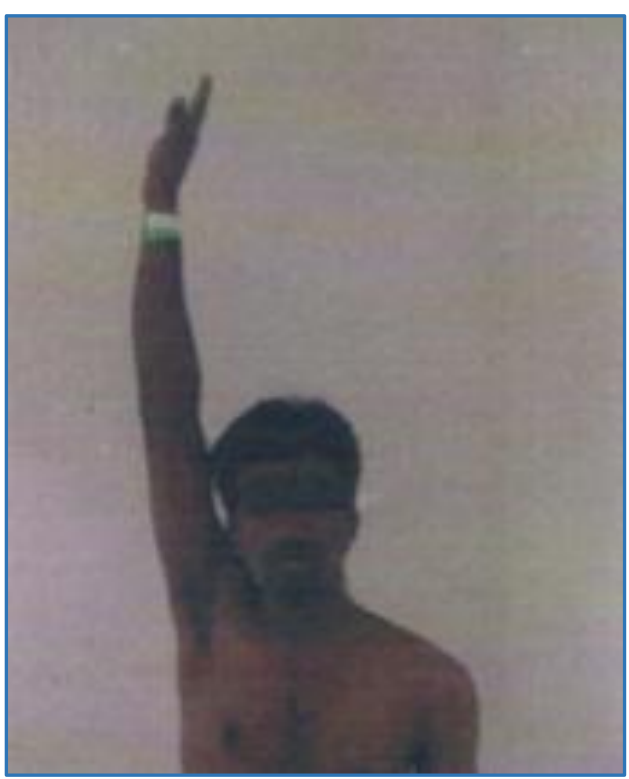

Abduction 


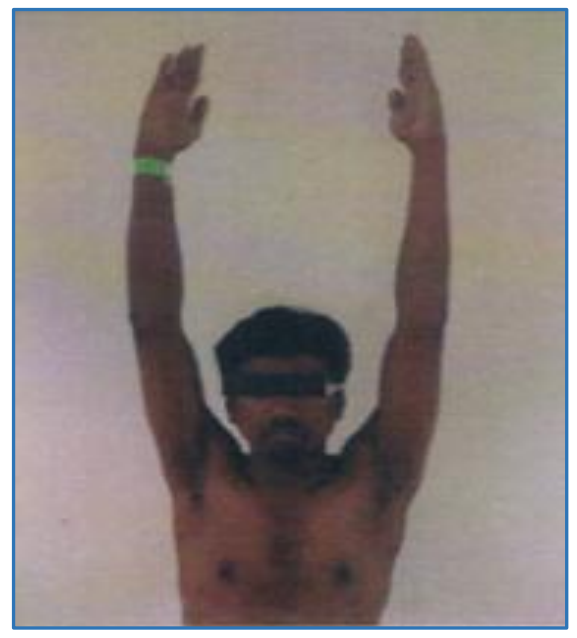

External Rotation

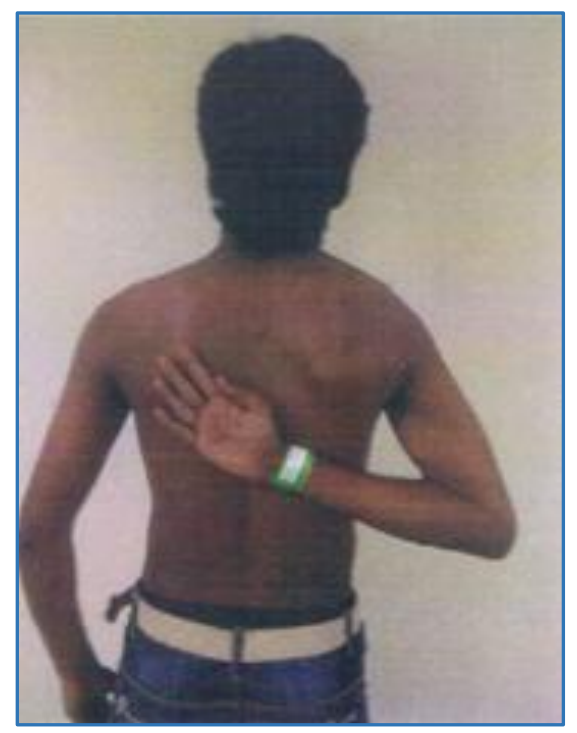

Internal Rotation

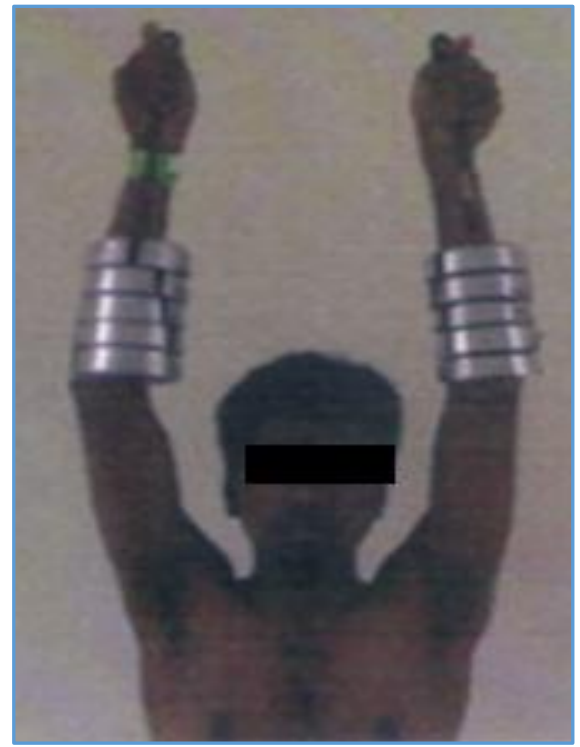

Strength of Abduction
OPERATIVE CASE 2 - 42yr/M -Good result

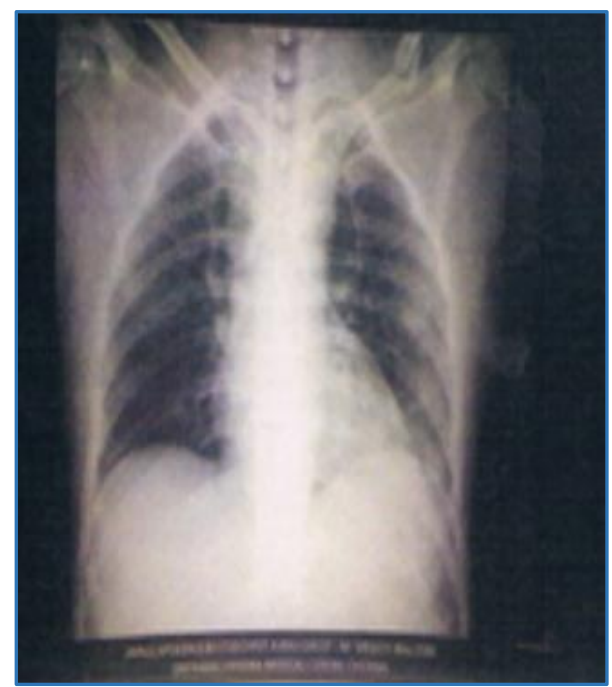

Preoperative

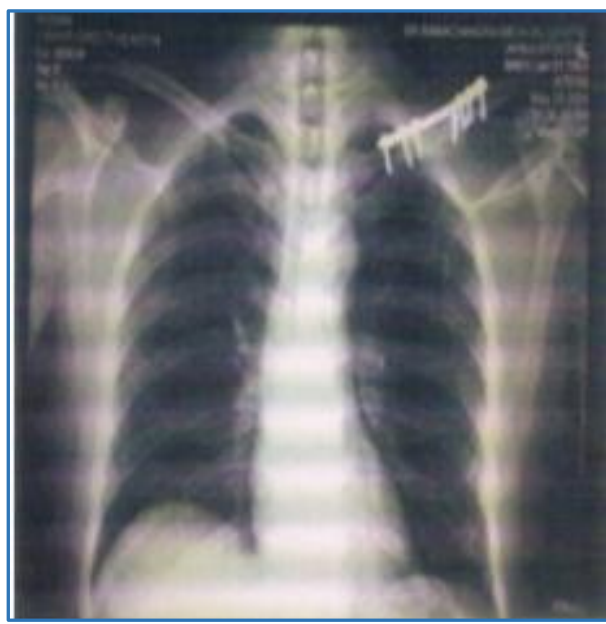

Postop - 1 year

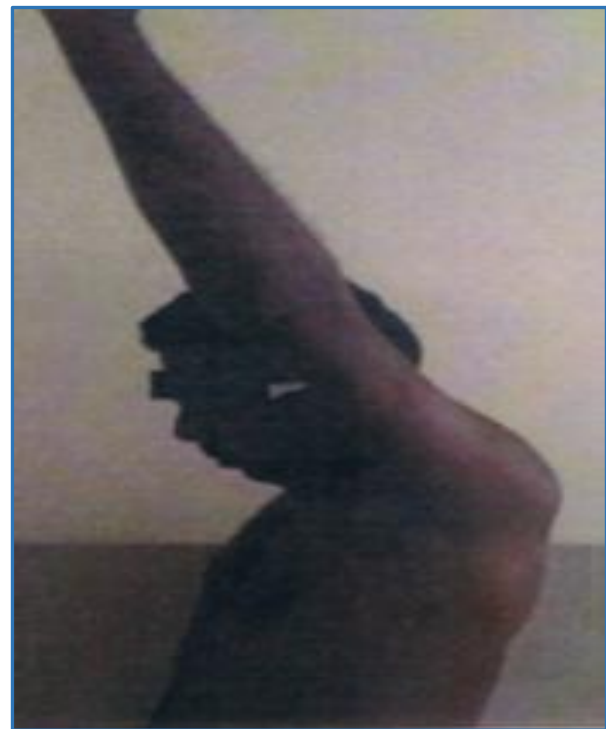

Flexion 


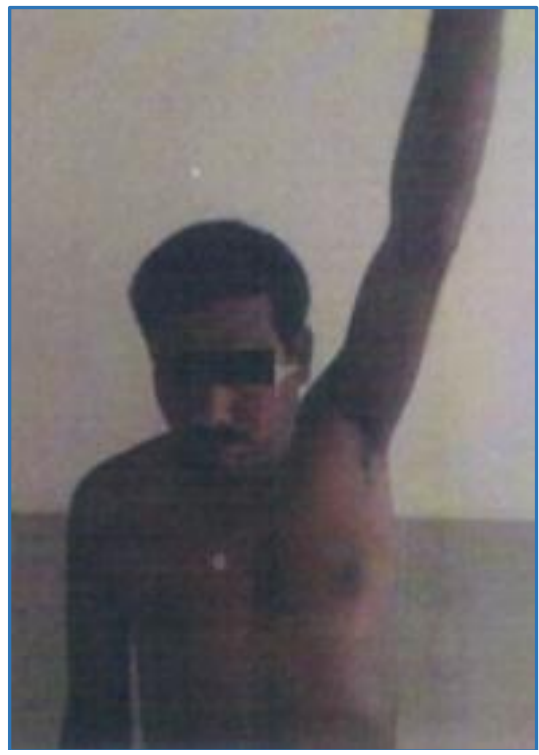

Abduction

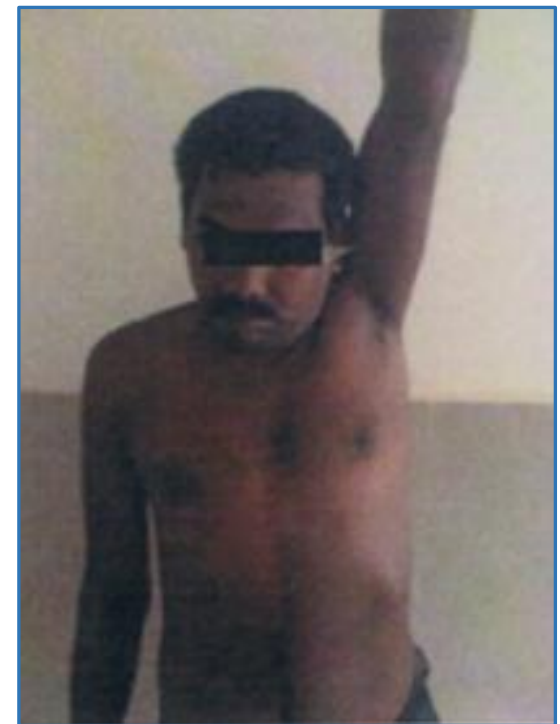

External Rotation

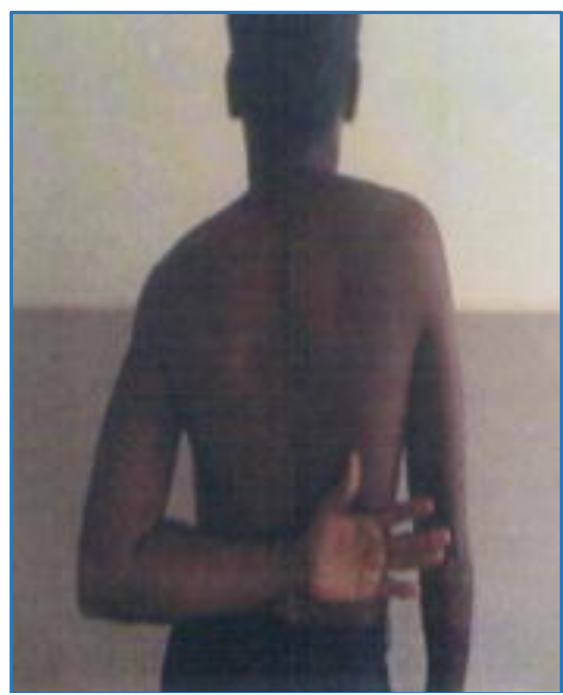

Internal Rotation
OPERATIVE CASE 3 - 54yr/M - Fair result

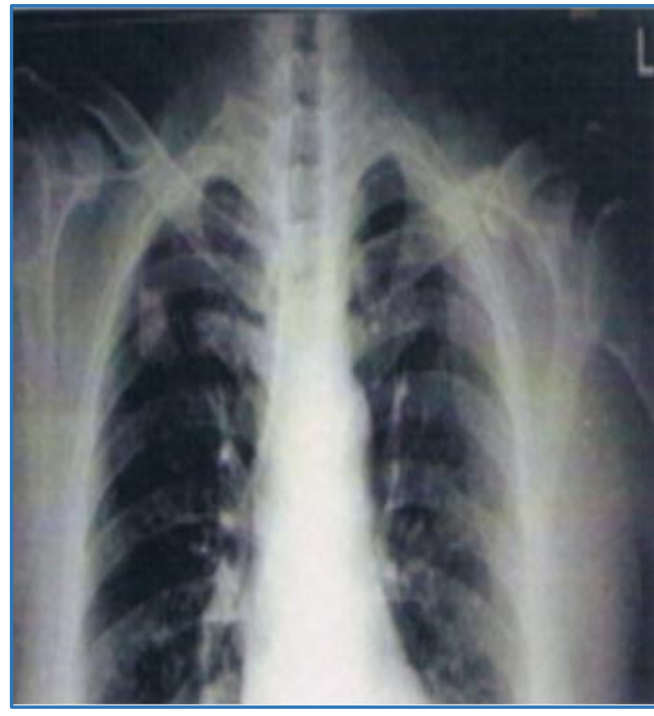

Preoperative

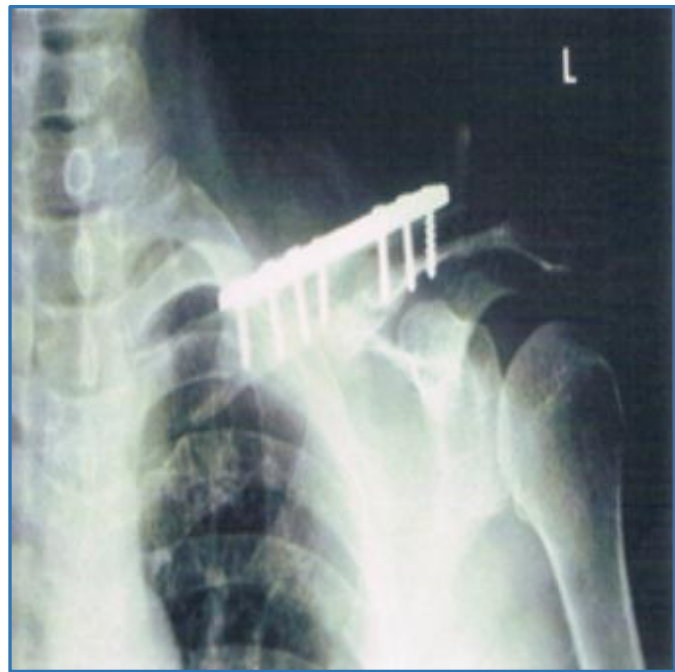

Postop 1 year

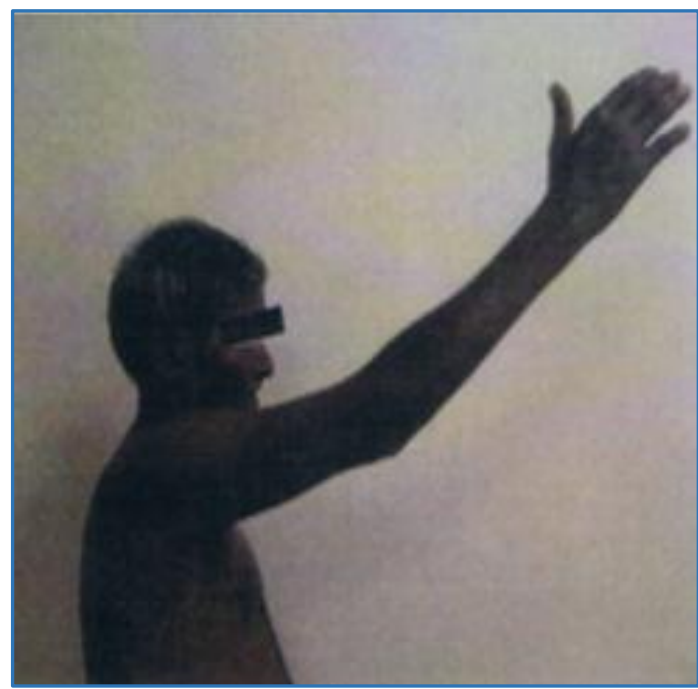

Flexion 


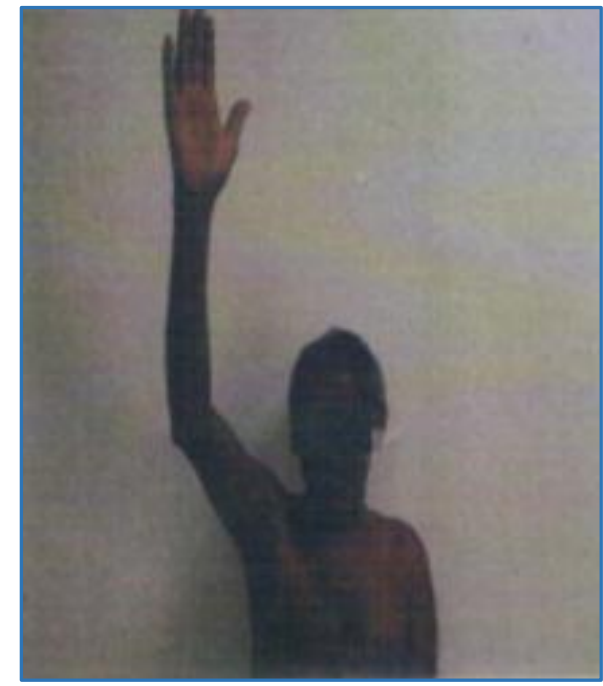

Abduction

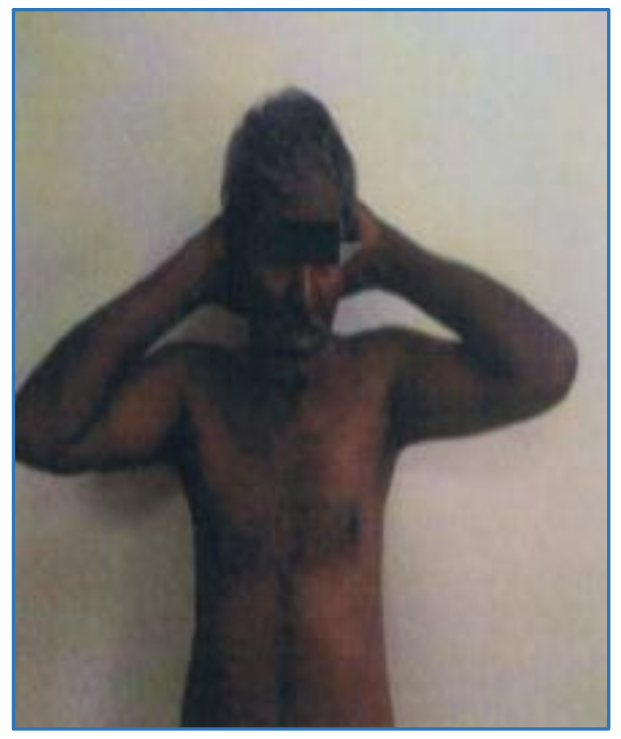

External Rotation

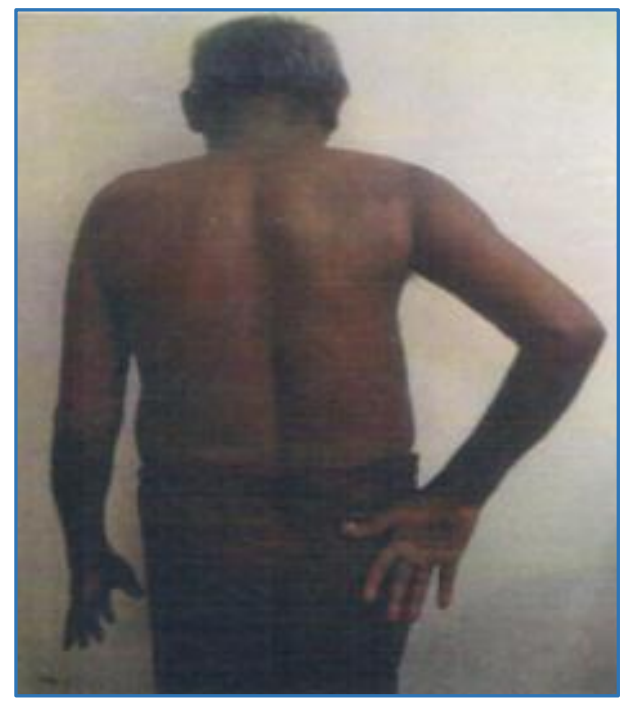

Internal Rotation
OPERATIVE CASE 4 - 50yr/Poor result with implant loosening

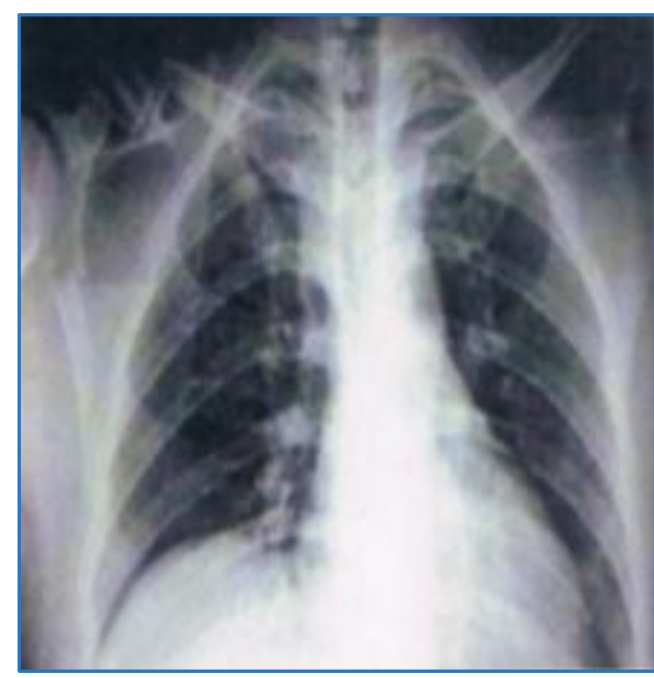

Preoperative

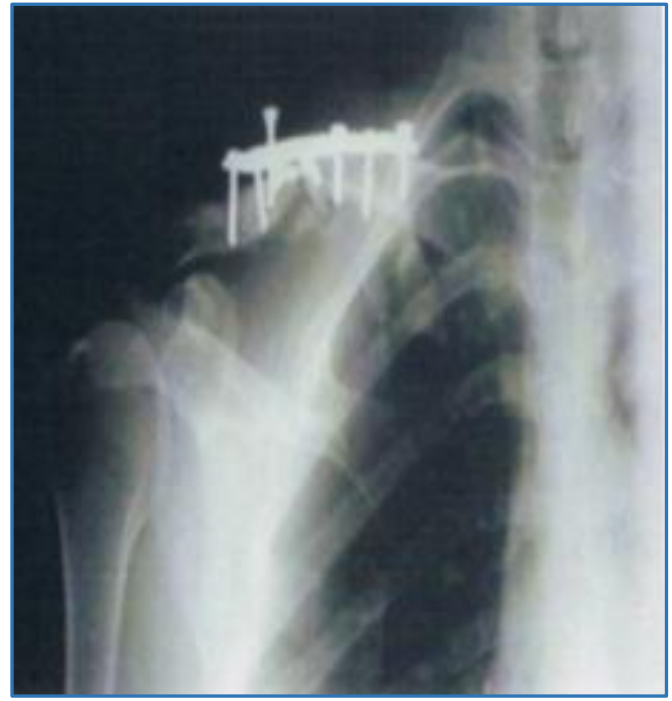

Postop 1 year

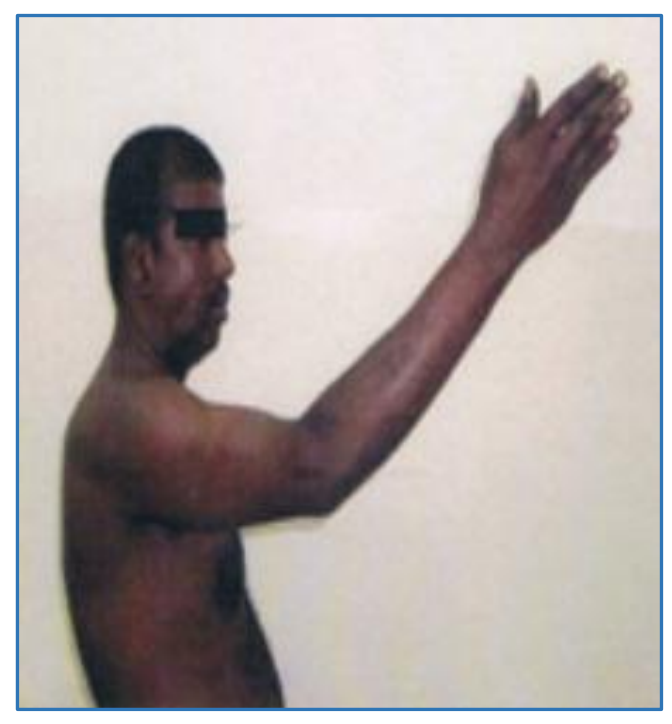

Flexion 


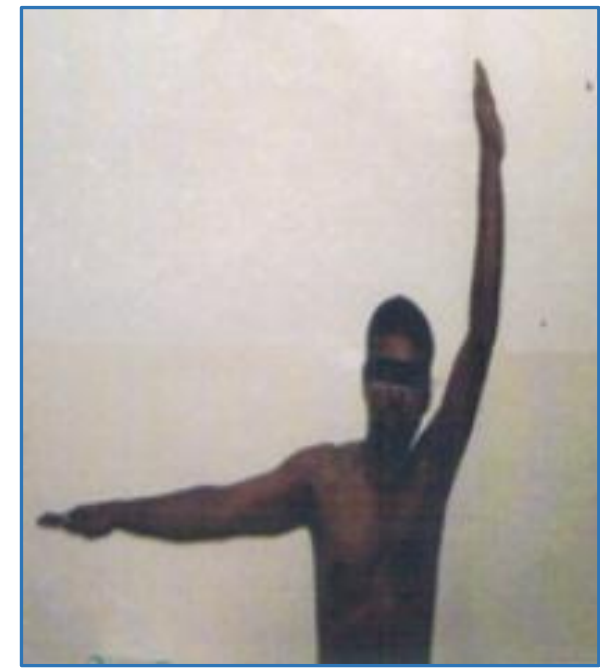

Abduction

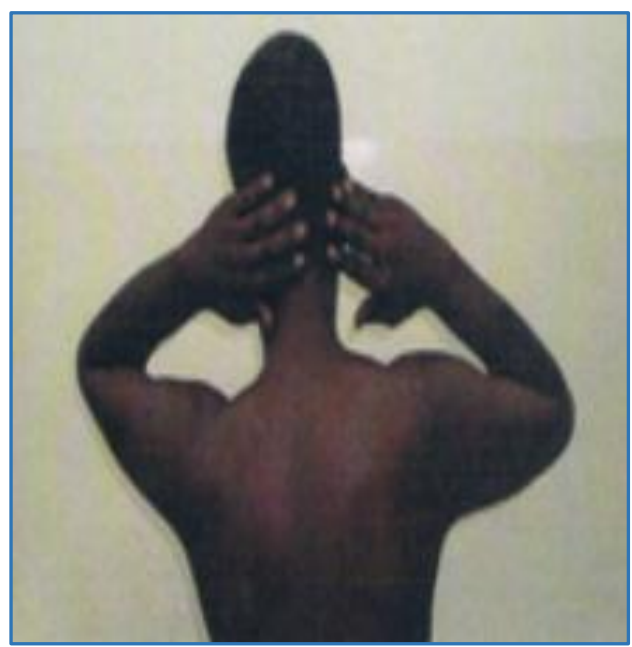

External Rotation

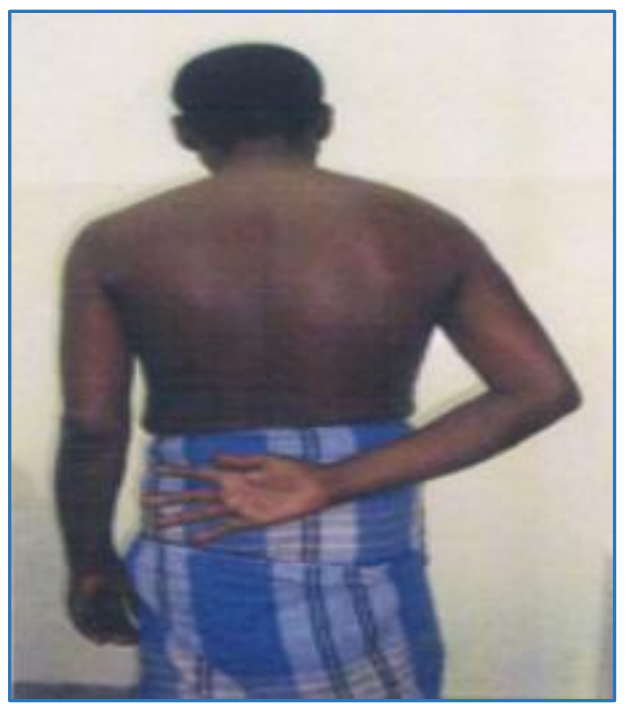

Internal Rotation
NONOPERATIVE CASE 1 - 26 yr/M - Excellent result

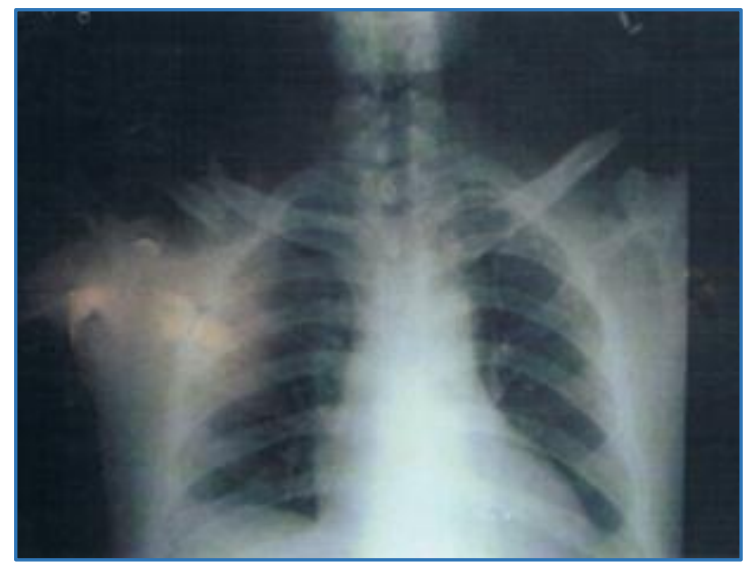

Immediate

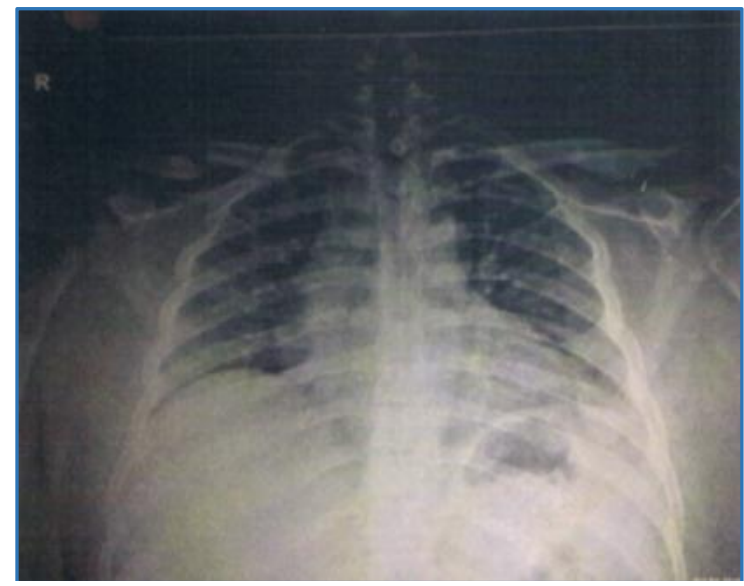

1 year

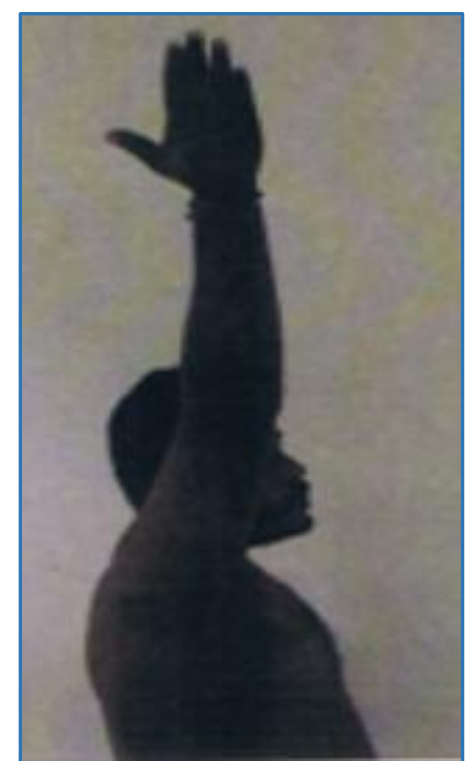

Flexion 


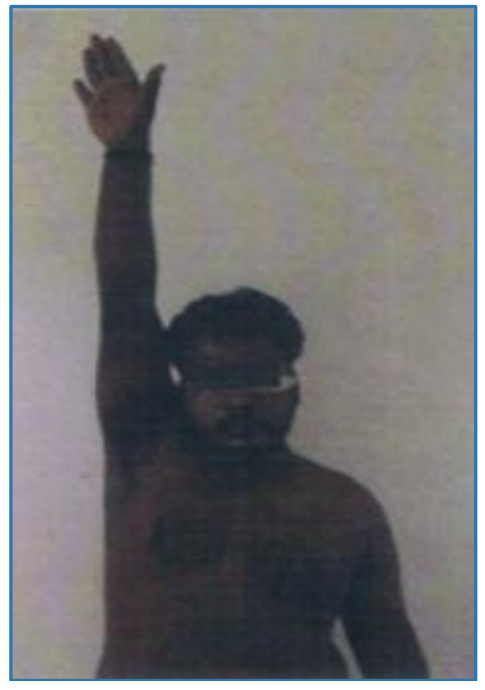

Abduction

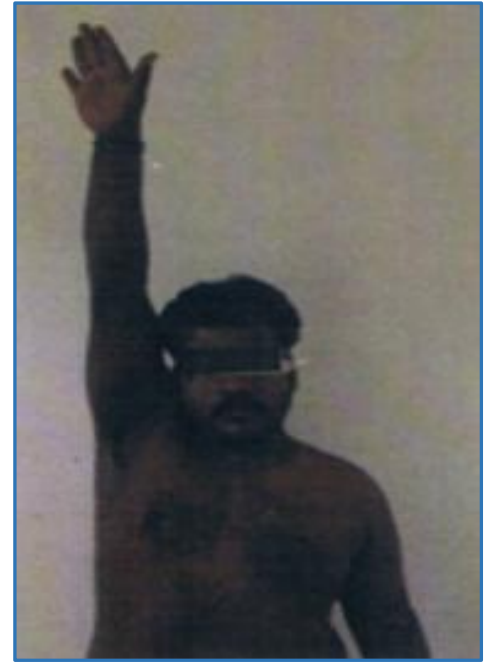

External Rotation

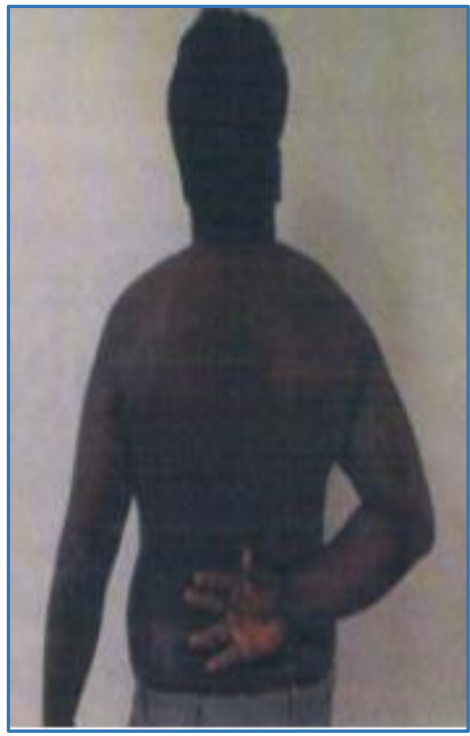

Internal Rotation

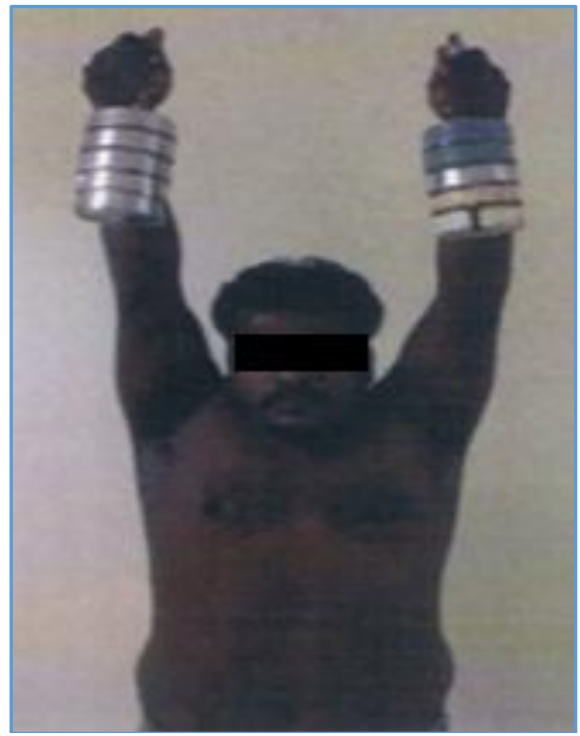

Strength of Abduction

NONOPERATIVE CASE 2 - 56 yr/M - Good result

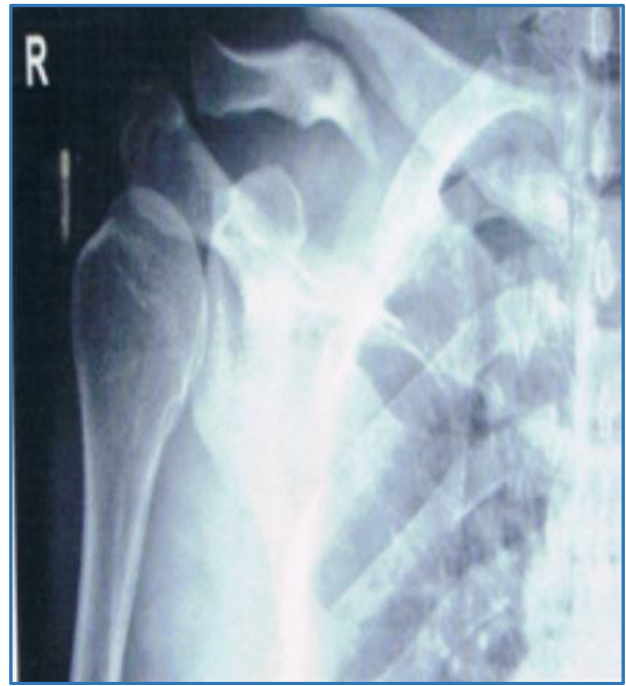

Immediate

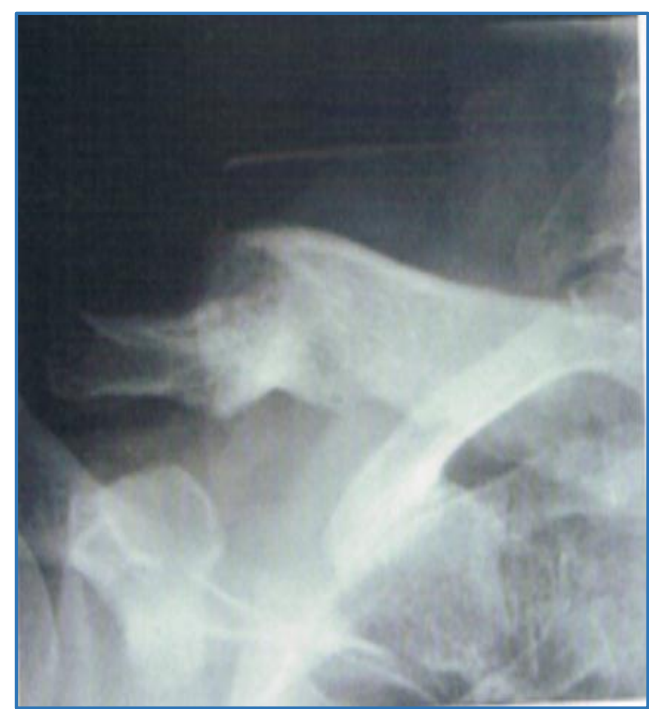

1 year 


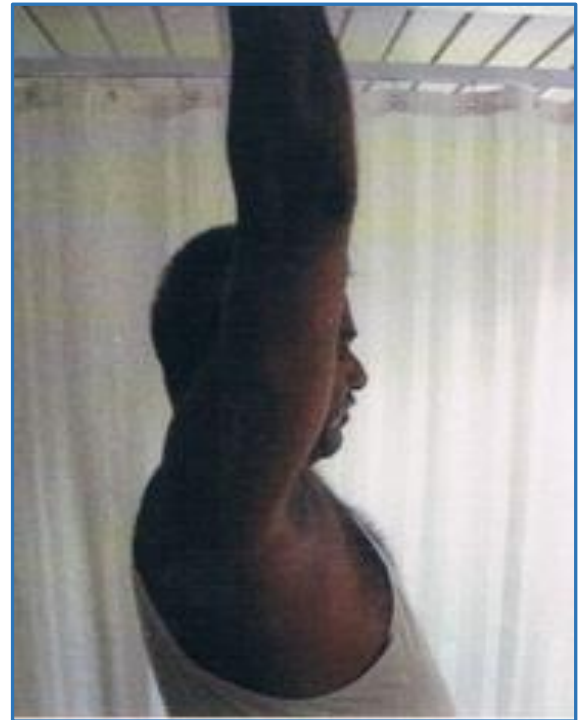

Flexion

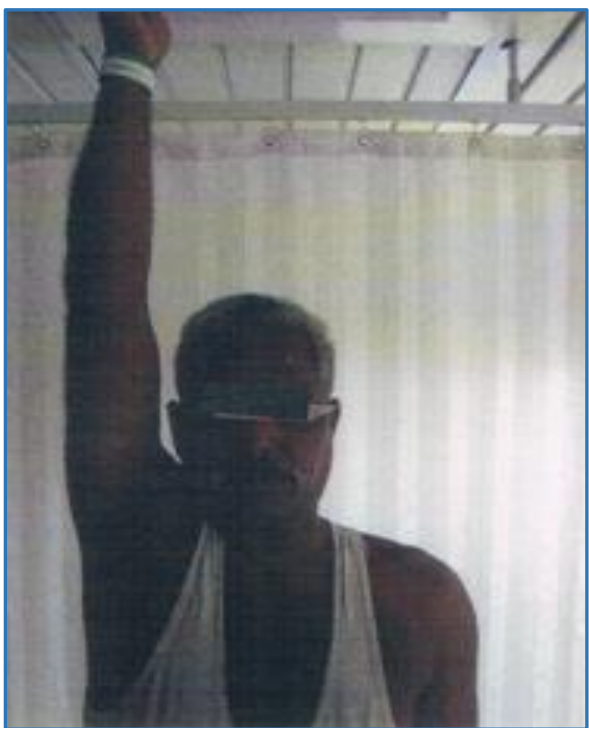

Abduction

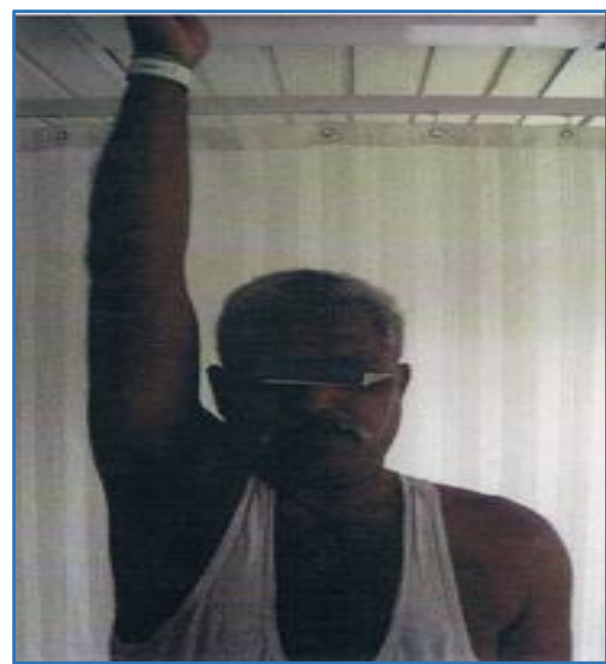

External Rotation

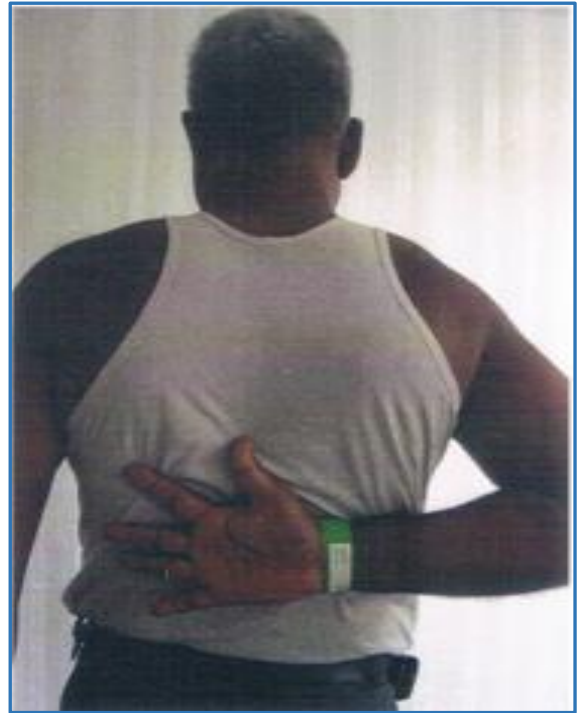

Internal Rotation

NON OPERATIVE CASE 3 - 63 yr/M - Fair result

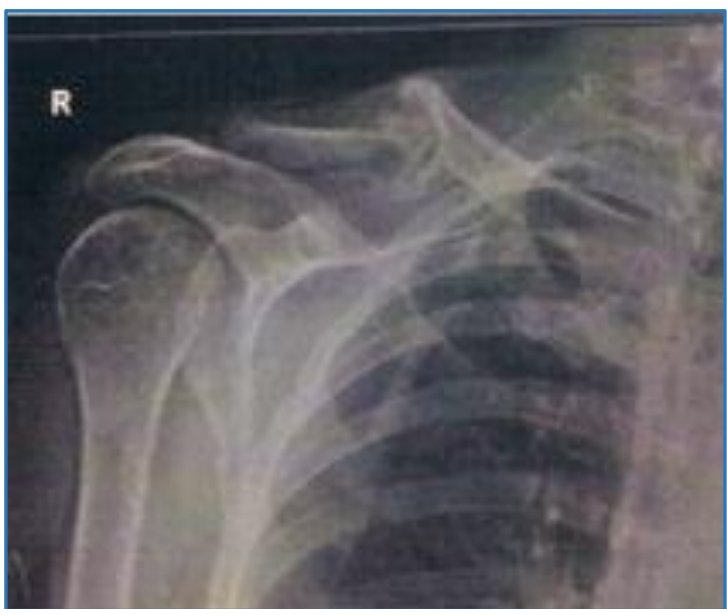

1 year

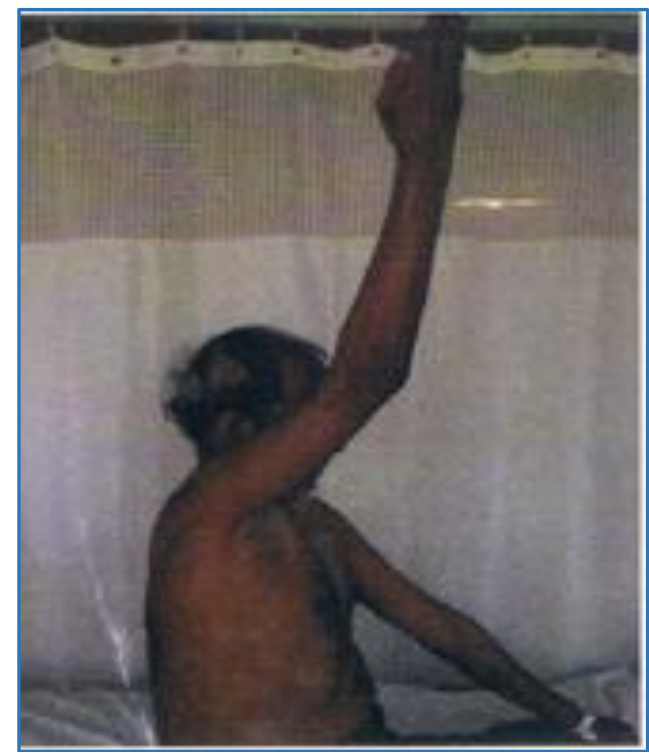

Flexion 


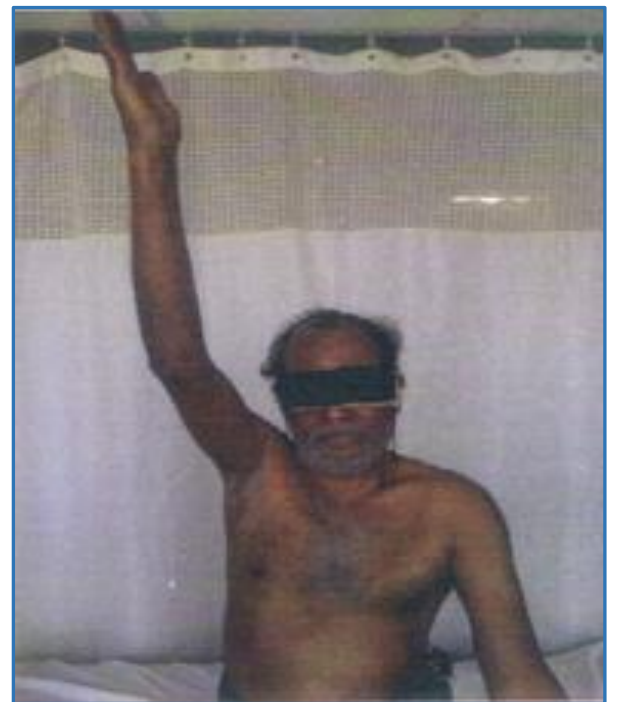

Abduction

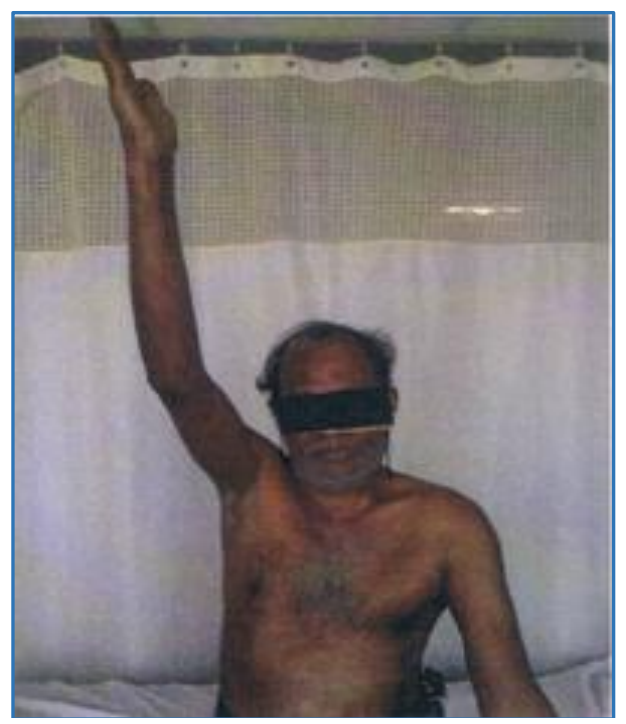

External Rotation

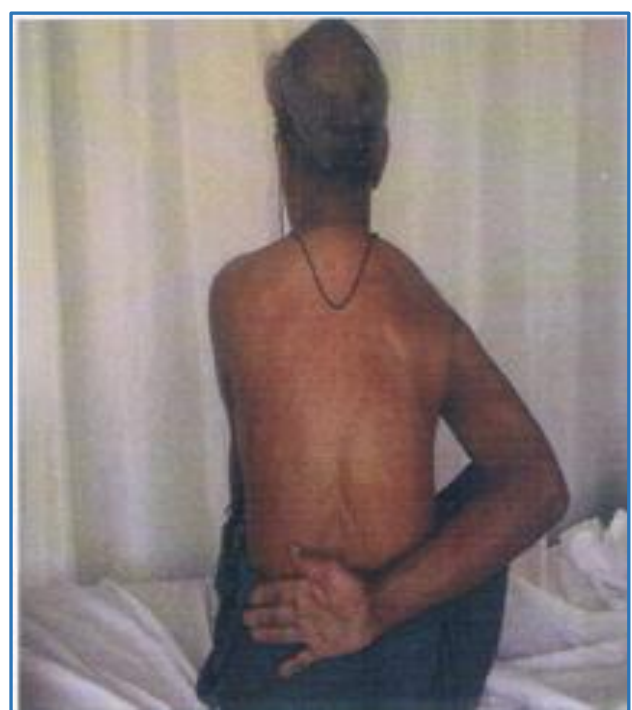

Internal Rotation

\section{NONOPERATIVE CASE 4 - 60 yr/M - Poor result}

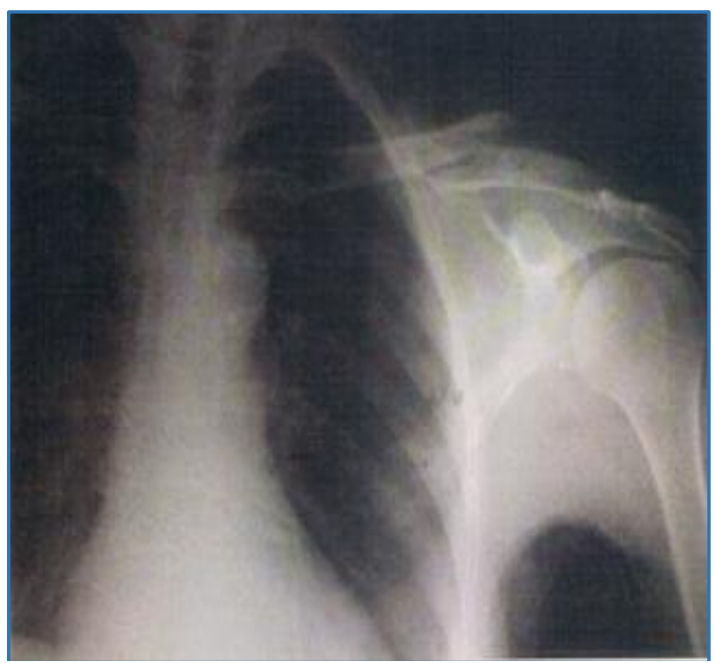

Immediate

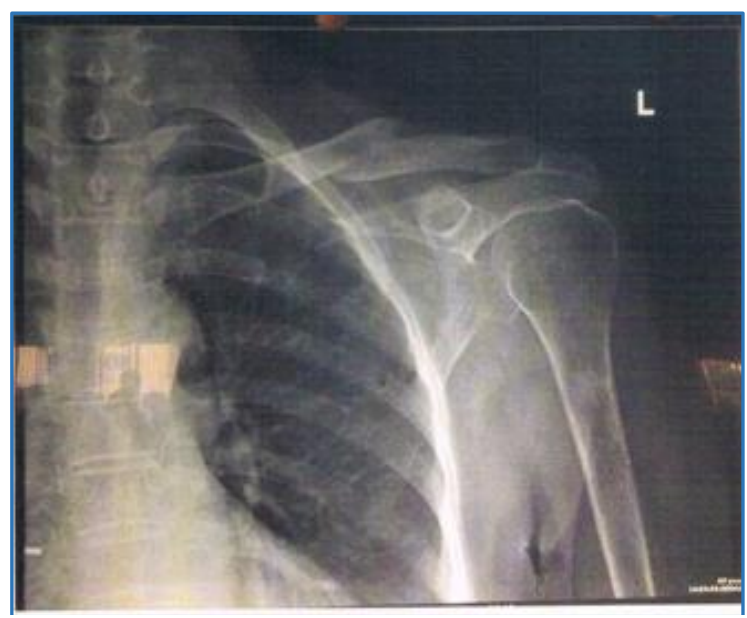

1 year

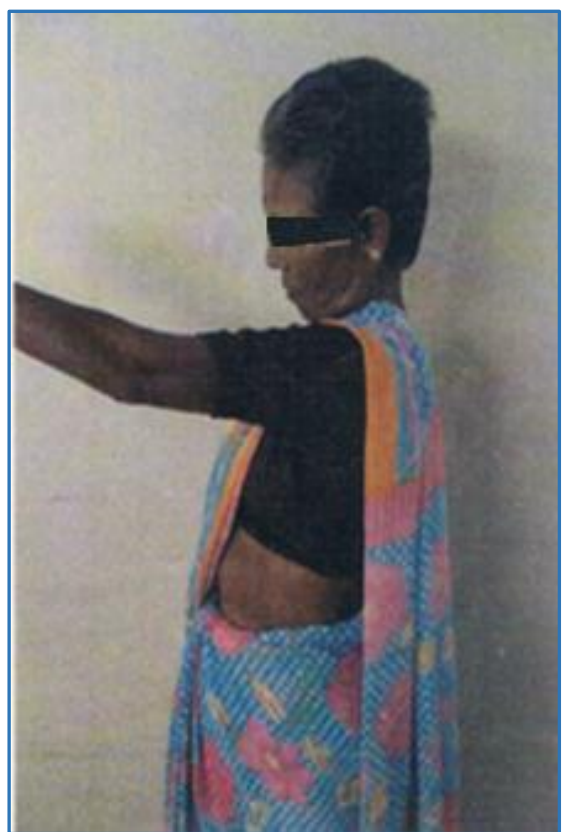

Flexion 


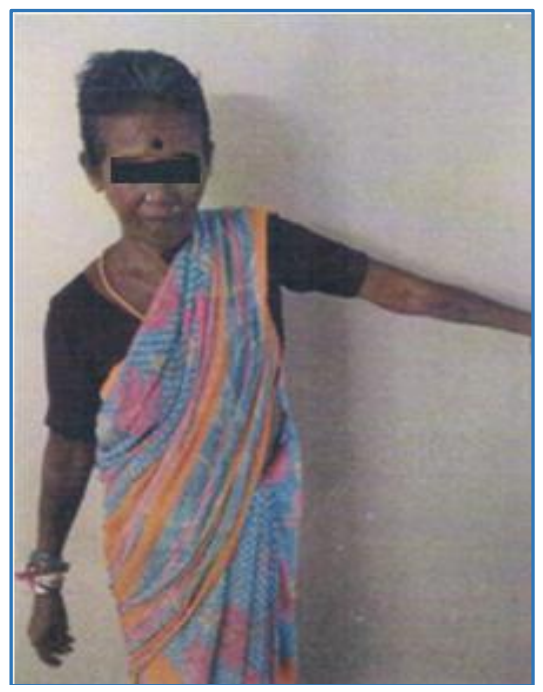

Abduction

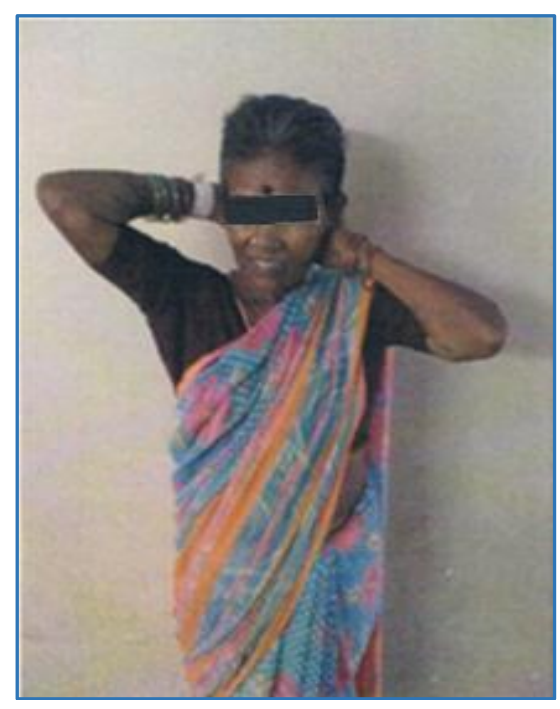

External Rotation

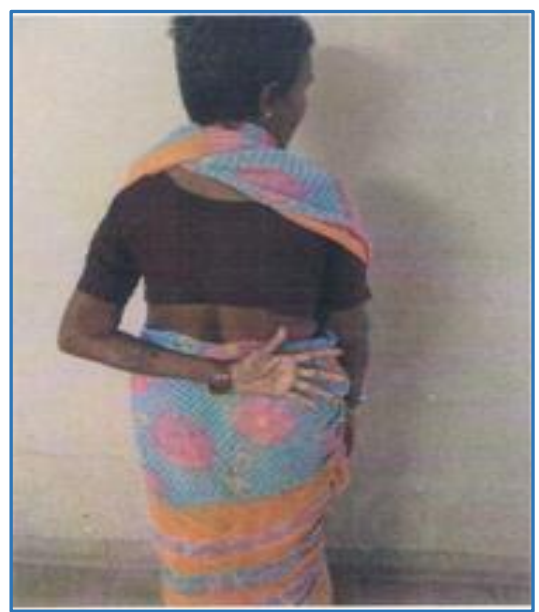

Internal Rotation

\section{CONCLUSION:}

- There were no significant difference in functional outcomes of patients with midshaft clavicle fractures treated by surgery and non-surgically.

- Shortening of more than two centimeters did not affect the final scores and functional outcome.

- Younger patients seems to do better than the old patients on comparison.

\section{BIBLIOGRAPHY:}

1. Robinsoncm, Edinburgh Classification. JBJS 1998; 80 Br: 476.

2. Constant CR, Murley AH.A Clinical method of functional assessment of shoulder. Clin.Orthop.Relat.Res 1987 Jan;(214): 160-4.

3. Hoppenfeld Stanley and De Boer PIET. Surgical Exposures in Orthopaedics. $4^{\text {th }}$ edition, Lippincott Wolter, 2009.

4. S.Terry Canale, James H.Beaty. Campbell's Operative Orthopaedics. $12^{\text {th }}$ edition. Mosby Elsevier; 2013.

5. Rockwood, Charles. A, David P. Green, James D. Heckman, and Robert W. Bucholz. Fractures in Adults and Children. $8^{\text {th }}$ edition. Lippincott Williams \& Wilkins, 2014.

6. Chan KY, Jupiter JB, Leffert RD, Marti R. Clavicle malunion. J Shoulder Elbow Surg. 1999; 8; 287-90. 8287 1999.

7. Bosch U, Skutek M, Peters G, Tscherne H, emtension osteotomy in malunited clavicular fractures. J Shoulder Elbow Surg. 1998;7; 402-5, 74021998.

8. Basamania CJ. "Claviculoplasty" and intramedullary fixation of malunited, shortened clavicular fractures. J Shoulder Elbow Surg. 1999;8; 540, 85401999.

9. Zlowodzki M, Zelle BA, Cole PA, Jeray K, Mckee MD; Evidence-Based Orthopaedic Trauma Working Group. Treatment of midshaft clavicle fractures: Systemic review of 2144 fractures: On behalf of the evidence based orthopaedic Trauma Working Group. J Orthop Trauma. 2005;19: 504-7. 